\title{
DIREITOS HUMANOS, MIGRAÇÃO E SUSTENTABILIDADE DAS CIDADES BRASILEIRAS
}

\author{
Edson Roberto Siqueria Jr. ${ }^{1}$ \\ Émilien Vilas Boas Reis ${ }^{2}$
}

\begin{abstract}
RESUMO
Este artigo objetiva investigar como a sustentabilidade é viável, ou não, nas cidades brasileiras em razão da não efetividade dos direitos humanos fundamentais, especialmente os direitos sociais, no contexto histórico de migração e formação daquelas. A investigação passa pelas ideologias que fundamentam os direitos fundamentais e, considerado o meio ambiente como direito fundamental, concluiu pela obrigatoriedade de ação, através de políticas públicas, para efetivação dos direitos sociais sob pena de ser inviável a preservação daquele. Foi utilizada metodologia jurídico-teórica com interdisciplinaridade com a geografia e a história a partir de raciocínio hipotético-dedutivo, com técnicas de pesquisa bibliográfica.
\end{abstract}

Palavras-chave: sustentabilidade; direitos fundamentais; cidades; ideologia; migração.

\section{HUMAN RIGHTS, MIGRATION AND SUSTAINABILITY OF BRAZILIAN CITIES}

\begin{abstract}
This article aims to investigate how sustainability is feasible or not in Brazilian cities due to the non - effectiveness of fundamental human rights, especially social rights, in the historical context of migration and formation of those. The investigation goes through the ideologies that underlie fundamental rights and, considering the environment as a fundamental right, concluded by the obligation of action, through public policies, to realize social rights under penalty of being unviable the preservation of it. Legal-theoretical methodology was used with interdisciplinarity with geography and history based on hypothetical-deductive reasoning, with bibliographic research techniques.
\end{abstract}

Keywords: sustainability; fundamental rights; cities; ideology; migration.

\section{INTRODUÇÃO}

O presente trabalho tem como objeto de estudo a formação dos direitos fundamentais humanos sob o viés das diferentes ideologias que a informaram para descortinar como a

\footnotetext{
${ }^{1}$ Mestrando em direito ambiental pela Escola Superior Dom Helder Câmara, Especialista em direito tributário pelo IBET e em direito público pela Fadivale. Professor de direito constitucional e tributário.

${ }^{2}$ Pós-doutor em filosofia pela Faculdade do Porto (FLUP-Portugal). Doutor e mestre em filosofia pela Pontifícia universidade católica do rio Grande do Sul (PUCRS). Graduado em Filosofia pela Universidade Federal de Minas Gerais (UFMG).
} 
sustentabilidade é possível nas cidades brasileiras no contexto histórico de migração e formação daquelas.

Apresenta-se, como hipótese, a impossibilidade de desenvolvimento sustentável, nas cidades brasileiras, considerada sua formação e inexistência de planejamento, diante da ausência de direitos fundamentais que possibilitem a equidade social.

Busca-se, portanto, demonstrar como a ausência de direitos fundamentais nas cidades causado pela inexistência de planejamento diante do fluxo migratório e o crescimento impediram e impedem o desenvolvimento sustentável.

A pesquisa é relevante na medida em que as populações urbanas brasileiras crescem exponencialmente e o Estado tem como obrigação, assumida em tratados e, internamente, na Constituição, proporcionar direitos humanos fundamentais em todas as dimensões, notadamente o meio ambiente equilibrado por meio do desenvolvimento sustentável.

A pesquisa é bibliográfica, sendo realizada por meio do raciocínio hipotéticodedutivo e metodologia jurídico-teórica com interdisciplinaridade com a geografia e a história.

O trabalho está dividido em três capítulos abordando-se, no primeiro, a evolução dos direitos humanos fundamentais a partir das diferentes ideologias que os fundamentaram na história. Investiga-se os direitos fundamentais a partir do liberalismo, do socialismo e do Estado social.

Passa-se, na segunda parte, a tratar do meio ambiente como direito fundamental e as declarações de direitos que o consagraram.

No terceiro capítulo aborda-se a migração da população brasileira e a formação histórica das cidades analisando-se dados sobre a migração das populações rurais e os índices de crescimento demográfico relacionando-os aos direitos humanos fundamentais.

\section{DIREITOS HUMANOS FUNDAMENTAIS, MEIO AMBIENTE E IDEOLOGIA}

A relação entre direitos fundamentais, meio ambiente e ideologia é fundamental e merece investigação do pesquisador para apontar como os valores presentes na sociedade, em determinado momento, contribuíram para a gênese e evolução dos direitos fundamentais até a "geração" que credita aos direitos difusos e coletivos a condição de fundamentais. 
Compreender os valores que informam os direitos fundamentais é essencial ao presente estudo na medida em que a migração, a formação e o crescimento não planejado das cidades negligenciou às populações mais pobres os direitos fundamentais ao desenvolvimento humano.

Neste ponto, importante a investigação das ideologias ${ }^{3}$ que informaram a evolução dos direitos humanos, especialmente o liberalismo e o socialismo, como nascedouros, em seu contexto e pela tensão entre elas, daqueles direitos.

\subsection{Direitos humanos, liberalismo e socialismo}

O liberalismo, como doutrina que fundamentou o agir humano em suas diversas áreas, é identificável por trazer consigo características que, sem qualquer pretensão de esgotamento do assunto neste texto, lutavam contra o absolutismo medieval em busca da liberdade e da proteção à propriedade privada.

Assim, o indivíduo possuía direitos originários e inalienáveis, propriedade e liberdade, baseados, num primeiro momento, no jusnaturalismo e no individualismo. Nesse contexto, a propriedade privada dos meios de produção é elemento essencial à economia de mercado que, para Adam Smith (1996), deve reger-se segundo suas próprias leis, sem intervenção.

Calha o ensinamento de Bonavides, ao tratar do liberalismo:

O estado é armadura de defesa e proteção da liberdade. Cuida-se, com esse ordenamento abstrato e metafísico, neutro e abstencionista de Kant, de chegar a uma regra definitiva que consagre, na defesa da liberdade e do direito, o papel fundamental do Estado.

Sua essência há de esgotar-se numa missão de inteiro alheamento e ausência de iniciativa social. (BONAVIDES, 2004, p. 41).

O iluminismo fundamentava, assim, o pensamento e tinha em autores como Locke, Voltaire, Montesquieu, Rousseau e Adam Smith a sustentação filosófica necessária.

${ }^{3} \mathrm{O}$ termo ideologia é utilizado no sentido de conjunto de crenças religiosas, políticas, morais e filosóficas que expressam certa fase do desenvolvimento econômico e social e servem à defesa dos interesses dominantes (ABBAGNAMO, 2007). 
Em Locke a terra foi dada por Deus aos homens para que, através da racionalidade, retirassem seu sustento e sobrevivência, e, assim, justifica a apropriação da terra ao afirmar que "Deus deu o mundo aos homens em comum; mas desde que lhos deu para seu benefício e para que dele retirassem as comodidades da vida de que fossem capazes, não se poderia supor que Ele pretendesse que ela permanecesse sempre comum e inculta.” (LOCKE, 2006, p. 44).

Rolf Kuntz relata a construção no pensamento de Locke que justifica a doutrina liberal afirmando que "com o pensamento lockiano, liberdade e propriedade se haviam convertido em termos quase indissociáveis" (KUNTZ, 2004, p. 91). Locke considera a propriedade como inerente à condição humana, como verdadeiro "direito natural do indivíduo que não pode ser violado pelo Estado" (MELO, 2006, p. 85).

A limitação do poder é também pedra fundamental no pensamento liberal como argumenta Bonavides ao tratar do pensamento de Locke e Montesquieu:

Com efeito, permite o reconhecimento desse traço estudo bem metodizado e compreensivo do papel que Locke e Montesquieu desempenharam no campo das ideias políticas, a par dos caminhos que ambos perlustraram como expoente da teoria liberal, para chegarem, afinal, a esse resultado comum e coincidente: a redução do poder. (BONAVIDES, 2004, p. 167).

Assim, como mecanismo de limitação do poder, o racionalismo individualista liberal não admitia intervenção do Estado, a este caberia a tutela dos direitos individuais, especialmente liberdade e propriedade privada, quando não respeitados, omitindo-se para os demais direitos.

Nesse contexto, como expressão dos valores aqui relatados, surgiram declarações de direitos como a Magna Carta de 1215, a Petição de Direitos de 1628 e a Lei de Habeas Corpus em 1679, além da Declaração de Direitos da Virginia de 1776 e a Declaração Universal dos Direitos do Homem de 1789, tomadas aqui com caráter exemplificativo.

No aspecto econômico, a livre concorrência, para o liberalismo, se renovaria a partir dos seus próprios mecanismos com o surgimento de novas oportunidades em razão da retirada do mercado daqueles que não conseguissem sobrepor-se aos demais concorrentes.

Nessa primeira fase do liberalismo capitalista, reitera-se, não se admitia intervenção na economia cabendo ao mercado reger-se por suas próprias regras e a satisfação das necessidades individuais levaria, como consequência necessária, à satisfação das necessidades coletivas (SMITH, 1996). 
Entretanto, a organização e sofisticação dos meios de produção permitiu a acumulação de capital, elemento essencial à lógica liberal capitalista, com a formação de monopólios, abuso da liberdade econômica e a eliminação dos concorrentes, dessa maneira, desequilibrando o mercado.

A liberdade formal expressada na livre concorrência e no livre mercado, ao permitir a concentração econômica, excluiu grande parte da população das benesses do sistema e implicou na necessidade de ação do Estado para manutenção do próprio sistema capitalista.

Essa liberdade, desprovida de qualquer intervenção do Estado que considerasse as desigualdades econômicas, sociais e pessoais, permitia a opressão do mais fraco pelo mais forte cabendo àquele, historicamente, a fome e a miséria.

Nesse contexto de miséria e exploração proporcionada pela classe burguesa sobre a classe desprovida dos meios de produção, especialmente após a revolução industrial, era iminente uma revolução proletária. "O século XIX, em especial a sua primeira metade, cheirava a revolução. Em 1848, Marx esperava, para o ano seguinte, uma guerra mundial como resultado de uma insurreição que considerava inevitável por parte da classe operária inglesa" (WEFFORT, 2004, p. 231).

No Manifesto comunista, Marx e Engels conclamam para a revolução ao afirmar que os comunistas apoiam "qualquer movimento revolucionário contra a ordem social e política vigente" (MARX; ENGELS, 2000 p. 108) e ainda determinam que "os comunistas não se rebaixem a dissimular suas opiniões e seus fins. Declaram abertamente que seus objetivos só podem ser alcançados pela derrubada violenta de toda a ordem social existente" (MARX; ENGELS, 2000 p. 109).

Era necessária, considerado esse contexto histórico, uma teorização que permitisse a legitimação do ativismo e, assim, Marx desenvolve o materialismo histórico, a partir da superação da epistemologia do idealismo e do materialismo real, para a libertação do homem (VIEIRA, 1996).

A convergência entre a teorização e o ativismo possibilitou a revolução socialista posto que, de outra forma, "a práxis revolucionaria estaria fadada ao teorismo ou ao ativismo, caso um dos elementos, a teoria ou a prática, fosse único determinante desse processo.” (VIEIRA, 1996, p. 29).

O materialismo histórico pressupõe o homem social dependente da estrutura de uma sociedade historicamente determinada e das relações de produção e de trabalho nela inserida. 
Parte da permanente luta de classes na sociedade capitalista em razão da propriedade privada e da exploração do trabalho para a inevitabilidade da revolução no momento em que o capitalismo atingir seu ponto máximo de concentração de capital e empobrecimento do trabalhador (ABBAGNAMO, 2007).

Ao lado desse movimento socialista, as guerras e as mazelas humanas históricas do século XX indicaram, sobremaneira, a inadequação da liberdade formal, como tradicionalmente defendida pelo liberalismo para o desenvolvimento da humanidade e o contraponto do socialismo marxista impuseram a necessidade do Estado agir para a efetivação da igualdade material e diminuição das desgraças humanas.

\title{
2.2 Direitos humanos e Estado Social
}

A luta de classes entre burguesia e proletariado e as desgraças e misérias humanas geradas pelo capitalismo "puro" nos séculos XIX e XX, colocaram a humanidade entre a revolução socialista violenta e o capitalismo darwnista.

São importantes, nesse aspecto, as palavras de Paulo Bonavides:

\begin{abstract}
Em face das doutrinas que na prática levavam, como levaram, em nosso século, ao inteiro esmagamento da liberdade formal, com a atroz supressão da personalidade, viram-se a Sociologia e a Filosofia do liberalismo burguês compelidas a uma correção conceitual imediata da liberdade, um compromisso ideológico, um meiotermo doutrinário, que é este que vai sendo paulatinamente enxertado no corpo das Constituições democráticas.

Nestes, ao cabo de cada uma das catástrofes que ensanguentaram o mundo no presente século, testemunhamos o esforço de fazer surdir a liberdade humana resguardada em direitos e garantias.

Direitos que se dirigem para o setor material da mesma liberdade, enriquecida aí, com as conquistas operadas na esfera social e econômica, e garantias que se orientam no sentido de preservar o velho conceito formal de liberdade. (BONAVIDES, 2004, p. 59).
\end{abstract}

Assim, a tensão entre o estado capitalista e o estado socialista, este último socializante da propriedade privada e dos meios de produção, exigiram do capitalismo concessões necessárias à sua sobrevivência, especialmente na primeira metade do século XX.

Sobre os direitos humanos para a proteção do trabalhador pondera Fabio Konder Comparato que "os direito humanos de proteção do trabalhador são, portanto, fundamentalmente anticapitalistas, e, por isso mesmo, só puderam prosperar a partir do 
momento histórico em que os donos do capital foram obrigados a se compor com os trabalhadores". (COMPARATO, 2007, p. 55).

Como alternativa ao capitalismo que abrangia mercado livre, propriedade privada como direito natural, individualismo, liberdade e igualdade formal, sem a ruptura traumática proposta pelo socialismo científico, surge o Estado social a partir da dualidade teórica e prática entre capitalismo e socialismo.

O Estado social não representa rompimento radical com as bases capitalistas do Estado liberal. Não rejeita a propriedade privada nem a economia de mercado, mas, essencialmente, desloca-se do individualismo não intervencionista, caracterizador daquele, para acrescentar preocupações sociais e coletivas ao Estado, com a necessária ação deste na sociedade e na economia.

Ensina Paulo Bonavides (2004, p. 59):

\begin{abstract}
Quando o Estado, coagido pela pressão das massas, pelas reivindicações que a impaciência do quarto estado faz ao poder político, confere, no Estado Constitucional ou fora deste, os direitos do trabalho, da previdência, da educação, intervém na economia como distribuidor, dita salário, manipula a moeda, regula preços, combate o desemprego, protege os enfermos, dá ao trabalhador e ao burocrata a casa própria, controla as profissões, compra a produção, financia as exportações, concede crédito, institui comissões de abastecimento, provê necessidade individuais, enfrenta crises econômicas, coloca na sociedade todas as classes na mais estreita dependência de seu poderio econômico, político e social, em suma, estende sua influência a quase todos os domínios que dantes pertenciam, em grande parte, à área de iniciativa individual, nesse instante o estado pode, com justiça, receber a denominação de estado social.
\end{abstract}

A liberdade, neste modelo de Estado, deixa de ser de uma classe, como no liberalismo originário, e passa a ser para todas as classes. A ação do Estado pretende minimizar as desigualdades abandonando seu aspecto formal e privilegia a igualdade material tendo, como consequência, consagração de direitos atinentes não mais somente ao indivíduo direitos individuais como propriedade e liberdade, mas, também, direitos sociais e, posteriormente, coletivos e difusos.

No Estado Social, para a consecução de seus fins, é indispensável a ação deste na economia e na sociedade para efetivação dos direitos sociais conquistados de modo que haja igualdade material e justiça distributiva.

Surgem, sob esta perspectiva, cartas que consagram direitos humanos sob viés que transcende os direitos individuais e são a síntese dos modelos liberal capitalista e do modelo socialista tais como a Constituição Francesa de 1848 e, notadamente, a Constituição 
Mexicana de 1917 e a Constituição de Weimar de 1919, além da Declaração Universal dos Direitos Humanos de 1948 e da Convenção Internacional sobre a prevenção e punição do crime de genocídio também em 1948 (COMPARATO, 2007).

\title{
3 MEIO AMBIENTE COMO DIREITO HUMANO FUNDAMENTAL E SUSTENTABILIDADE
}

A evolução dos modelos de Estado guarda relação com a evolução dos direitos fundamentais na medida em que, como exposto, o Estado liberal individualista fundamentavase na liberdade e na propriedade privada e o Estado social, como síntese da dialética entre liberalismo e socialismo, acresceu direitos sociais ao rol de direitos sem, contudo, excluir os direitos conquistados com as revoluções liberais.

Consolidadas as duas gerações ou dimensões anteriores, posto que não excludentes, as preocupações se voltam para direitos coletivos e difusos, em especial para este estudo, o direito ao meio ambiente e à sustentabilidade.

Argumenta Paulo Bonavides:

\begin{abstract}
Com efeito, um novo polo jurídico de alforria do homem se acrescenta historicamente aos da liberdade e da igualdade. Dotados de altíssimo teor de humanismo e universalidade, os direitos da terceira geração tendem a cristalizar-se no fim do século $\mathrm{XX}$ enquanto direitos que não se destinam especificamente à proteção dos interesses de um indivíduo, de um grupo ou de um determinado Estado. Têm primeiro como destinatário o gênero humano mesmo, num momento expressivo de sua afirmação como valor supremo em termos de existencialidade concreta. (BONAVIDES, 2015, p. 583).
\end{abstract}

A partir da revolução industrial, com a evolução da tecnologia e os desastres ambientais suportados pela humanidade, despertou, o homem, para questões que envolvem o meio ambiente. Tais preocupações foram expressas em conferências internacionais como a declaração de Estocolmo em 1972 e a Rio 92.

A declaração de Estocolmo foi a primeira grande declaração na qual se evidencia a intenção de associar o desenvolvimento dos países às políticas ambientais capazes de garantir a sustentabilidade.

Tal declaração exprime a preocupação da comunidade internacional com o meio ambiente e os modelos de desenvolvimento adotados, estabelecendo no segundo item que "a 
proteção e a melhoria do ambiente humano constituem desejo premente dos povos do globo e dever de todos os Governos [...]." (ONU, 1972, p. 1).

O item sexto da Conferência das Nações Unidas Sobre o Meio Ambiente Humano Declaração de Estocolmo de 1972 - reconhece os danos causados pela humanidade e propõe a defesa e melhoramento do meio ambiente para as gerações presentes e futuras.

Após vinte anos, foi realizada, no Rio de Janeiro, a Conferência das Nações Unidas Sobre o Meio Ambiente e Desenvolvimento, que intentou atualizar e evoluir sua antecessora, conforme afirma expressamente o preâmbulo:

\footnotetext{
A Conferência das Nações Unidas sobre Meio Ambiente e Desenvolvimento, tendo se reunido no Rio de Janeiro, de 3 a 14 de junho de 1992, reafirmando a Declaração da Conferência das Nações Unidas sobre o Meio Ambiente Humano, adotada em Estocolmo em 16 de junho de 1972, e buscando avançar a partir dela, com o objetivo de estabelecer uma nova e justa parceria global mediante a criação de novos níveis de cooperação entre os Estados [...]. (ONU, 1992, p. 1).
}

Entre os 26 princípios que a compõe, é necessário destacar o terceiro que reafirma a sustentabilidade ao tratar que " $\mathrm{O}$ direito ao desenvolvimento deve ser exercido de modo a permitir que sejam atendidas equitativamente as necessidades de desenvolvimento e de meio ambiente das gerações presentes e futuras.” (ONU, 1992, p. 1).

Neste ponto, é mister, ainda, investigar o conceito de desenvolvimento sustentável que, segundo a Comissão Mundial sobre Meio Ambiente e Desenvolvimento, é "um desenvolvimento que faz face às necessidades das gerações presentes sem comprometer a capacidade das gerações futuras na satisfação de suas próprias necessidades” (THOMÉ, 2013, p. 59).

O desenvolvimento sustentável passa pela harmonização de três vieses indispensáveis para a satisfação das necessidades da geração presente sem comprometer as futuras, quais sejam: crescimento econômico, preservação ambiental e equidade social.

Aqui, calha destacar a equidade social necessária ao desenvolvimento sustentável e, ordinariamente, ausente nas ocupações urbanas nas grandes cidades dos países "em desenvolvimento".

Vale dizer, sem antecipar qualquer conclusão, a ausência de direitos humanos fundamentais nas ocupações urbanas nas cidades dos países "em desenvolvimento" pode impedir o desenvolvimento sustentável por lhe faltar pressuposto básico. 
Filosoficamente, pode-se encontrar o fundamento da sustentabilidade no pensamento de Hans Jonas que rompe com a ética tradicional e atribui responsabilidade às presentes gerações com relação às consequências de seus atos para com as gerações futuras ao repensar o imperativo categórico Kantiano como: "aja de modo a que os efeitos da tua ação sejam compatíveis com a permanência de uma autêntica vida sobre a Terra" (JONAS, 2006, p. 47).

Pode-se concluir, portanto, que os direitos humanos, antes preocupados com a satisfação das necessidades do homem exclusivamente, se voltam para questões ambientais e agregam novo fator à análise daqueles direitos.

Importante o ensinamento do professor Klaus Bosselmann (2010, p. 75):

\begin{abstract}
A partir de uma perspectiva centrada na sustentabilidade, os direitos precisam ser complementados por obrigações. A mera defesa de direitos ambientais não alteraria o conceito antropocêntrico de direitos humanos. Se, por exemplo, os direitos de propriedade continuarem sendo compreendidos de maneira isolada e separada das limitações ecológicas, eles irão reforçar o antropocentrismo e incentivar um comportamento abusivo.
\end{abstract}

Indispensável, portanto, afirmar que o Estado deve agir intervindo na sociedade e na economia para inserir nas políticas públicas a proteção ao meio ambiente e a sustentabilidade por meio da efetivação dos direitos humanos nas cidades.

\title{
4 POPULAÇÃO E MIGRACÕES NO BRASIL
}

É da natureza humana a necessidade de viver em sociedade e, desta forma, o desenvolvimento do homem se deu, historicamente, dentro da convivência com seus pares.

Reis ressalta a importância fundamental das cidades na cultura ocidental e, após, sua fundamentação reflexiva com os helênicos ao firmar que "a cidade, para Aristóteles, torna o homem um ser complexo ao possibilitar que suas capacidades (fala e relação social, por exemplo) sejam efetivadas [...]" (REIS, 2015, p. 11).

Assim, as aglomerações humanas deram origem às primeiras vilas que se desenvolviam a partir de atividades rurais como a agricultura e criação de animais e, assim, formavam muitas cidades brasileiras.

O desenvolvimento industrial, o desemprego no campo e até guerras deram causa a movimentos migratórios que modificaram a relação campo/cidade no Brasil e no mundo. Da Europa migraram para o Brasil cerca de sete milhões de pessoas, fixando-se definitivamente 
quatro milhões e quinhentos mil, a maioria na cidade de São Paulo (RIBEIRO, 2006, P. 177178).

O crescimento da população urbana brasileira foi exponencial a partir de 1960. Em 1950 a população urbana era de 18.782 .891 habitantes e a taxa de urbanização de $36,1 \%$. Em 1970 a taxa de urbanização aumentou para 55,9\% e a população urbana passava de 50 milhões (GIRARDI, 2008).

A população urbana brasileira, em 2000, era de 137.755 .550 habitantes, o que representou aumento de 633,4 \% em cinquenta anos como consequência do êxodo rural e do grande crescimento vegetativo da população (GIRARDI, 2008).

Entre as décadas de 1980 e 1990, São Paulo foi o estado que mais recebeu imigrantes - 2.638.297, seguido de Goiás - 598.356, Rio de Janeiro e Minas Gerais. A cada década, aproximadamente oito milhões de pessoas migraram no Brasil (GIRARDI, 2008).

Como consequência da migração e das altas taxas de natalidade a densidade demográfica passou de 6,1 hab./km2 em 1950 para 19,92 hab./km2 em 2000. As regiões sudeste e sul possuem as maiores densidades demográficas. Comparativamente à região norte com 3,3 hab./km2, a região sudeste tem densidade altíssima com 78,2 hab./km2 (GIRARDI, 2008).

\subsection{Crescimento das cidades e direitos humanos fundamentais.}

A partir da análise das ideologias que informaram o estado e a evolução dos direitos humanos fundamentais feita anteriormente, é possível analisar os dados estatísticos para verificar o crescimento exponencial das cidades e, assim, a possibilidade de promoção da sustentabilidade.

O crescimento das cidades, especialmente nos países subdesenvolvidos, se deu a partir da migração campesina que, buscando melhores condições de vida, migrou para as cidades e se alocou em regiões não adequadas à moradia.

Paulo, comentando Seabra relata:

\footnotetext{
Sobre os recém-egressos do campo exerceu um fascínio da cidade, tanto pela materialidade que guarda todos os tempos, (as catedrais, os mosteiros, jardins e praças públicas) como pelas ideias tomadas em circulação. A literatura fez crer que a cidade chegou a ser promessa de um mundo melhor porque dela foi veiculada para a cidade inteira uma imagem de mundo com novas possibilidades, principalmente para os migrantes rurais que deixavam os arados e as enxadas. (PAULO, 2010, p. 177).
} 
A falta de planejamento público para receber aqueles que migraram gerou o crescimento desordenado da cidade e a formação de periferias sem estrutura adequada ao recebimento do fluxo migratório.

Paulo afirma (2010, p. 178):

As favelas geralmente se concentram em áreas que não deveriam ser habitadas, ou seja, na maioria das vezes essas habitações são construídas de forma irregular. Nesses locais encontramos pessoas vivendo totalmente à margem da sociedade, uma vez que tais favelas não possuem nenhuma infraestrutura e na maioria das vezes sequer possuem saneamento básico.

O crescimento desordenado da cidade, portanto, retira da população condições mínimas de vida digna na medida em que a habitação em locais impróprios e sem acesso a serviços públicos de saúde, educação, saneamento básico, entre outros, impede o desenvolvimento humano.

As ocupações irregulares fruto da migração e do crescimento populacional desordenado se dão, preponderantemente, em locais impróprios e com degradação do meio ambiente.

O desmatamento da mata atlântica, a ocupação de áreas de risco, a contaminação do solo pelo descarte inadequado de lixo e esgoto são exemplos de externalidades negativas causadas pelo crescimento não planejado das cidades.

A ocupação dos espaços urbanos sem planejamento, consequência da migração e da industrialização, afeta decisivamente os direitos humanos fundamentais em razão da ausência de saúde, educação, saneamento e, ainda, agressões ao meio ambiente.

Importante o ensinamento de Guerra apud Davis (2014, p. 261)

\begin{abstract}
Nas megalópoles, metrópoles e grandes cidades com extensivas áreas peri-urbanas e suburbana, a expansão horizontal, a alta densidade urbana, a degradação quase completa de recursos naturais vitais (aquíferos, bacias hidrográficas, mangues, ecossistemas litorâneos, etc.) aliadas ao aumento do tráfego, à poluição aérea, à destruição da cultura urbana e do direito à cidade da classe trabalhadora, à privatização do espaço público e à fuga dos ricos para enclaves fortificados têm tornado as áreas urbanas insustentáveis ambientalmente.
\end{abstract}

A ação do Estado, neste contexto, é essencial para a efetivação dos direitos humanos fundamentais em observância à ideologia constitucional consagrada na Constituição Brasileira de 1988. 
O Estado Brasileiro deve, para preservação do meio ambiente e promoção do desenvolvimento sustentável, buscar a efetivação dos direitos sociais nas cidades. A inexistência de serviços públicos de saúde e educação, bem como as ocupações urbanas não planejadas realizadas pelas populações marginalizadas, impedem o desenvolvimento sustentável e, por consequência, produzem danos ao meio ambiente.

Sem políticas públicas de desenvolvimento sustentável que racionalizem o crescimento das cidades, bem como proporcione o acesso a serviços públicos às populações marginalizadas não será possível preservar o meio ambiente para as futuras gerações.

Com efeito, a sustentabilidade passa pela efetivação dos direitos humanos fundamentais em todas as dimensões e, especialmente, dos direitos sociais dentro das cidades que, na sua gênese e crescimento, negligenciaram condições de vida digna à maior parte de seus habitantes.

\section{CONSIDERAÇÕES FINAIS}

Os direitos humanos fundamentais evoluíram a partir de ideologias como o liberalismo, o socialismo e o Estado Social, somando-se os direitos conquistados nos diferentes momentos históricos sem exclusão dos anteriores.

O meio ambiente e a sustentabilidade, como direitos fundamentais, surgem após a preocupação do Estado com os direitos individuais e sociais, assim como a ocorrência de catástrofes ambientais em maior escala com o advento da revolução industrial.

A partir do reconhecimento do meio ambiente como direito fundamental e da necessidade de preservação para as gerações futuras, o Estado tem o dever de implementar políticas públicas para proporcionar o desenvolvimento sustentável.

Neste ponto, como parte essencial da sustentabilidade, vale ressaltar a equidade social. A sustentabilidade reclama a efetivação dos direitos fundamentais, notadamente os direitos humanos com viés social, como condição indispensável para a preservação do meio ambiente para as futuras gerações.

Nas cidades brasileiras, em razão do crescimento demográfico ocasionado pela migração e as altas taxas de natalidade, bem como a omissão do Estado em planejar o meio ambiente urbano, os direitos sociais não são efetivos, em regra, faltando àquelas: saúde, educação, saneamento básico, entre outros. 
Neste contexto, inexiste equidade social é, portanto, necessária a ação do Estado Brasileiro, por meio de políticas públicas que promovam os direitos humanos fundamentais, especialmente os sociais, para as populações marginalizadas e, a partir daí, o desenvolvimento sustentável com a preservação do meio ambiente para as gerações vindouras. 


\section{REFERÊNCIAS}

ABBAGNAMO, Nicola. Dicionário de filosofia. Tradução de Alfredo Bosi. 5. ed. São Paulo: Martins Fontes, 2007

BONAVIDES, Paulo. Curso de direito constitucional. 30. ed. São Paulo:Malheiros, 2015.

Do Estado liberal ao Estado Social. 7. ed. São Paulo:Malheiros, 2004.

BOSSELMANN, Klaus. Direitos humanos, meio ambiente e sustentabilidade. In SARLET, Ingo Wolfgang (Org.). Estado Socioambiental e direitos fundamentais. Porto Alegre: Livraria do Advogado, 2010.

BRASIL. Constituição da República Federativa do Brasil de 1988. Disponível na internet em <http://www.planalto.gov.br/ccivil_03/constituicao/constituicao.htm >. Acesso em: $20 \mathrm{de}$ maio de 2016.

COMPARATO, Fábio Konder. A afirmação histórica dos direitos humanos. 5. ed. São Paulo: Saraiva, 2007.

CANOTILHO, J. J. Gomes; MENDES, Gilmar F.; SARLET, Ingo W.; STRECK Lenio L. (Coords.). Comentários á constituição do Brasil. São Paulo: Saraiva/Almedina, 2013.

CAVALCANTI, Clóvis (Org.). Meio Ambiente, desenvolvimento sustentável e políticas públicas. São Paulo, Cortez Editora, 1999.

DERANI, Cristiane. Direito ambiental econômico. São Paulo: Saraiva, 2009.

D'ISEP, Clarissa Ferreira Macedo. Direito ambiental econômico e a ISO 14000: análise jurídica do modelo de gestão ambiental e certificação ISO 14001. 2. ed. São Paulo: Revista do Tribunais, 2009.

; NERY JUNIOR, Nelson; MEDAUAR, Odete (Coord.). Políticas públicas ambientais. São Paulo: Revista dos Tribunais, 2009.

FONSECA, João Bosco. Direito econômico. 5. ed. Rio de Janeiro: Forense, 2007.

GALDINO, Flávio. Introdução à teoria do custo dos direitos: direitos não nascem em árvores. São Paulo: Lumen Juris, 2005.

GIRARDI, Eduardo Paulon. Atlas da questão agrária brasileira. Ribeirão Preto, 2008. Disponível em: http://www2.fct.unesp.br/nera/atlas/caracteristicas_socioeconomicas_b.htm. Acesso em 13 de junho de 2016;

GUERRA, Eliana Costa. Questão urbana e ambiental em tempos de crise do capital: configurações e particularidades no Brasil contemporâneo. Revista Política Pública. São Luis, número especial, p. 257-267, jul. 2014. 
JONAS, Hans. O Principio Responsabilidade: ensaio de uma ética para a civilização tecnológica. Rio de janeiro: Contraponto: ED PUC-RIO, 2006.

LOCKE, John. Segundo tratado sobre o governo civil. Tradução de Magda Lopes e Marisa Lobo da Costa. Petrópolis: Vozes, 2006.

KUNTZ, Rolf. Locke, liberdade, igualdade e propriedade. In CÉLIA, Galvão Quirino; VOUGA, Claudio; BRANDÃO, Gildo Marçal (Orgs.). Clássicos do pensamento político. 2. ed. São Paulo: Edusp, 2004, p. 91-119.

MARX, Karl; ENGELS, Friedrich. Manifesto do Partido Comunista. 9. ed. São Paulo: Global, 2000.

MELLO, Leonel Itaussu Almeida. John Locke e o individualismo liberal. In WEFFORT, Francisco Correa (Org.). Os clássicos da política. 13. ed. São Paulo: Editora Ática, 2006, p. 81-110, v. 1.

Organização das Nações Unidas. Declaração do Rio sobre Meio Ambiente e

Desenvolvimento. Rio de Janeiro, 1992. Disponível em

<http://onu.org.br/rio20/img/2012/01/rio92.pdf>. Acesso em: 22 de maio de 2016.

Organização das Nações Unidas. Conferência das Nações Unidas Sobre o Meio Ambiente Humano. Estocolmo, 1972. Disponível em

$<$ http://www.direitoshumanos.usp.br/index.php/Meio-Ambiente/declaracao-de-estocolmosobre-o-ambiente-humano.html>. Acesso em: 22 de maio de 2016.

PAULO, Rodolfo Fares. O desenvolvimento industrial e o crescimento populacional como fatores geradores de impacto ambiental. Revista Veredas do Direito. Belo Horizonte, v. 7, n. 13/14, p. 173-189, jan/dez. 2010.

PORTO-GONÇALVES, Carlos Walter. A globalização da natureza e a natureza da globalização. Rio de Janeiro: Editora José Olympio, 2015.

RIBEIRO, Darcy. O povo brasileiro: a formação e o sentido do Brasil. São Paulo: Companhia das Letras, 2006.

REIS, Émilien Vilas Boas. Cidade: um bem a ser protegido?. In: COSTA, Beatriz Souza; REIS, Émilien Vilas Boas; RIOS, Mariza; CARVALHO, Newton Teixeira (Coords.). Direitos fundamentais ambientais aplicados à cidade. 2. ed. Belo Horizonte: Del Rey, 2015.

SEABRA, Odette Carvalho de Lima. Territórios do uso: cotidiano e modos de vida. In: GEU - grupos de estudos urbanos (Org.). Cidades: Revista científica. v. 1, n. 2. Presidente Prudente: Grupo de Estudos Urbanos, 2004. 
SMITH, Adam. A riqueza das nações: investigação sobre sua natureza e suas causas. São Paulo: Editora Nova Cultural, 1996.

SOUZA, Washington Peluso Albino de. Primeiras linhas de direito econômico. 6. ed. São Paulo: LTR, 2005.

THOMÉ, Romeu. Manual de Direito Ambiental. 3. Ed. Salvador: Jus Podivm, 2013.

VIEIRA, Antonio Rufino. Filosofia marxista: uma análise das teses de Marx sobre Feuerbach. Princípios. Natal, n. 4, p. 27-50, jan/dez. 1996.

WEFFORT, Francisco Correa. Marx: política e revolução. In WEFFORT, Francisco Correa (Org.). Os clássicos da política. 10. ed. São Paulo: Editora Ática, 2004, p. 225-251, v. 2. 